\title{
Construction of Sustainable Scientific and Technological Innovation Team based on Sense of Achievement
}

\author{
Shiying Wang \\ College of Mechanical Engineering \\ Taiyuan University of Technology \\ Taiyuan, China \\ wangshiying@tyut.edu.cn \\ Xianhua Yao \\ College of Mechanical Engineering \\ Taiyuan University of Technology \\ Taiyuan, China \\ yaoxianhua@tyut.edu.cn
}

\author{
Weiguo Li \\ College of Mechanical Engineering \\ Taiyuan University of Technology \\ Taiyuan, China \\ liweguo@tyut.edu.cn
}

\begin{abstract}
In order to promote mass entrepreneurship innovation in a larger area and higher class deeper, a new innovation and entrepreneurship model is formed, the intelligent control robot innovation team of Taiyuan University of Technology aims to achieve a sense of achievement and they pay attention to the joint improvement in many aspects, adopt the mode of co-construction and win-win, mobilize the enthusiasm of the team, and realize the healthy, prosperous and sustainable development of the scientific and technological innovation team. Cultivate students' engineering quality, innovative practical ability and entrepreneurial ability so as to achieve innovation, creativity, innovation, entrepreneurship education and practice in one-stop, and train students' engineering practice and application ability in all round way to achieve the training goal of high-class scientific and technological innovation personnel.
\end{abstract}

Keywords: innovative spirit; practical ability; Sense of achievement

\section{INTRODUCTION}

In December 2006, the Engineering training Center of Taiyuan University of Technology was approved by the Ministry of Education of the People's Republic of China as the first batch of "National Experimental Teaching demonstration Center" for comprehensive engineering training. In the following year, according to the main working points of the Ministry of Education in 2007, "further deepening the educational and teaching reform, focusing on improving the scientific and cultural quality of students, focusing on cultivating students' innovative spirit and practical ability" Taiyuan University of Technology Intelligent Control Robot Innovation team" was established with the aim to build a public training platform for all professional students in the school to cultivate the innovative practical ability ${ }^{[1-4]}$. By setting up a research group made up of students of various majors, the research project driven by the interdisciplinary characteristics is adopted, and the independent design, hand-made, assembly and debugging of students are emphasized, the mechanism of mutual learning, unity and cooperation is formed to satisfy students' needs in studying multiple courses so as to achieve the training goal of "wide caliber, thick foundation, strong ability, brave innovation" ${ }^{[5-8]}$."Sense of achievement" is the sense of satisfaction achieved from the acquisition of a certain benefit. It embodies the social cognitive theory of self-worth and self-dignity satisfaction, and only all members of the science and technology innovation team have a sense of achievement can the science and technology team be sustainable: Researchers have strong cohesion, research projects are completed at a high level, and research results emerge endlessly, ${ }^{[9-10]}$.

\section{DESIGN OF TRAINING PROGRAMMES}

In order to achieve the goal of training, a cross training scheme of "moral cultivation, understanding, strong action, innovative thinking, and being successful" was constructed at the beginning of the team so that students could be trained to become a high level entrepreneurial talent of scientific and technological innovation during the research and development of intelligent control robot.

\section{A. Moral Cultivation}

Being moral is the basic quality that an outstanding creative talent shall be equipped with. Only a strong sense of social responsibility, rigorous scholarship, dare to question, dare to explore, and be friendly to others is equipped with can a person make proud achievements. Therefore, the team took "moral cultivation" as the primary training requirement by setting up the League branch on the research site, and the total branch of the robot team of Taiyuan University of Technology has four branches which are set up to give full play to the combat fortress role of the League Branch. We have trained a group of talents with both moral integrity and talent, as well as an excellent research and development team in science and technology.

\section{B. Understanding}

The team urges students to use basic theoretical knowledge through refining the deep theoretical problems in the research to broaden the students' learning and understanding of different professional knowledge, that is, "understanding". Students are required to draw up research programs with the help of theoretical guidance, solve the 
found problems by theoretical analysis, and interpret the new experimental phenomena to seek new theories or expand new theoretical explanations.

\section{Strong Action}

Students are required to have a strong ability in making, it is one of the cores of the innovative team in cultivating "artisan spirit", it is also the essential characteristic distinguishes it from other practical activities. Students not only require to complete, but to complete in a good quality. In the process of making a fully automatic tea making machine, Guopeng Zhang, a member of the robot team, continuously changed the shape of the temperature collection head and manually refined the surface texture structure in order to achieve the temperature detection sensitivity of a constant temperature device. After hundreds of experiments, the ideal temperature measurement requirements are finally met. This work won the first prize of the 2012 National College students' Mechanical Innovation Design Competition.

\section{Innovative Thinking}

Innovative thinking is an essential quality of an excellent man. The team adheres to innovation and experiments. Students are required to put forward a new idea in any research program. The robot must climb the vertical steps of 6 centimeters high. After analyzing and comparing the advantages and disadvantages of crawler, large diameter wheel roll, mechanism lifting and controlling jumping, leaping step has been chosen by the team. However, the leapfrog-onstage requires a large transient power of the motor and a high demand for design theory. Students consult the theoretical analysis of the data and use SOLIDWORKS software to repeatedly carry out dynamic simulation. Finally, leapfrog-onstage with rapid sped, love move and simple structure has been worked out by the team, and they win the championship in the competition.

\section{E. Being Successful}

There are two meanings of being successful. One is that all the design would turn into finished products. More than 280 pieces of work have been completed in the past ten years. Second, each student in the team must achieve the goal of training and become an outstanding scientific and technological innovator. The success rate of high quality personnel training is pursued, and more than 280 graduate students of the past ten years have been employed or study further in high quality.

\section{CONSTRUCTION OF INNOVATIVE TEAM}

Training programs for high-level talents must be supported by excellent teams, and an excellent innovative team must be endowed with healthy, high-class and sustainable development. The ten years' development of the innovative team of intelligent control robot for college students in Taiyuan University of Technology is a good explanation of the concept of construction.

\section{A. Healthy Development}

In order to achieve the healthy development of the team, a strict selection procedure and training system have been formulated first, and propaganda, training, assessment and employment have been continuously repeated every year.

In order to make qualified players grow quickly, in view of the characteristics of new players' growth, such as joy, hesitation, retreat, fear and outbreak, encouragement, help, counselling, resolution of difficulties and support have been adopted by the instructor to promote students' explosive growth. The relationship of emotion and time is shown in Fig. 1.

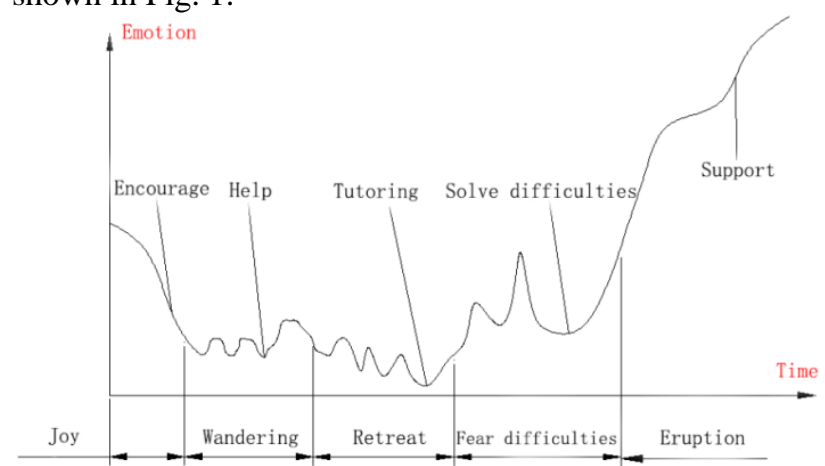

Fig. 1 Emotion-time diagram

\section{B. High-class Development}

High-class talents, projects and guidance teachers are the premises for the high-class development of a team. Therefore, we have adopted the training strategy of "education, transmission and help" for high-class students. The new content, new function and course of high-precision have been adopted; The new technology, new field and new demand of teachers' scientific research projects; The high-class construction plan of advanced topic sought by school-enterprise cooperation projects. Invite famous scholar in school, as well as well-known expert and high-class instructor outside the school to select the program.

\section{SUSTAINABLE DEVELOPMENT}

Sustainable development is another challenge faced by an innovation team. The team has three questions, including what can students of robot innovative team gain? What can an instructor get? And what can Taiyuan University of Technology get? After ten years' perfection, students are surprised to find that they have the opportunity to learn and communicate, improve their ability and social recognition. Teachers inadvertently found more opportunities to communicate with first-class universities at home and abroad, more attention from the enterprise to the research results, more teaching and scientific research projects and achievements, more recognition from school leaders as well as teachers and students; School leaders are surprised to find that they can compete with many colleges and universities, and cooperate with high-class universities to build innovative platform and win the attention of the society.

It is the team building that pays attention to the improvement in many aspects and adopts the mode of co-construction and win-win makes the innovation team of intelligent control robot of Taiyuan University of Technology realize the sustainable development. In the past 
10 years, there has been a steady increase in the number of awards in various competitions, with a total of 175 , shown in Fig. 2.Through practical training in the team, the students have strong practical ability, and they are favored by all kinds of employers. Among the more than 280 robot team members who have graduated, more than 20 students have studied abroad, and more than 20 have successfully started a business, and there are more than 80 studying further in well-known domestic universities, the rest have found the job they are interested in and achieved outstanding performance.

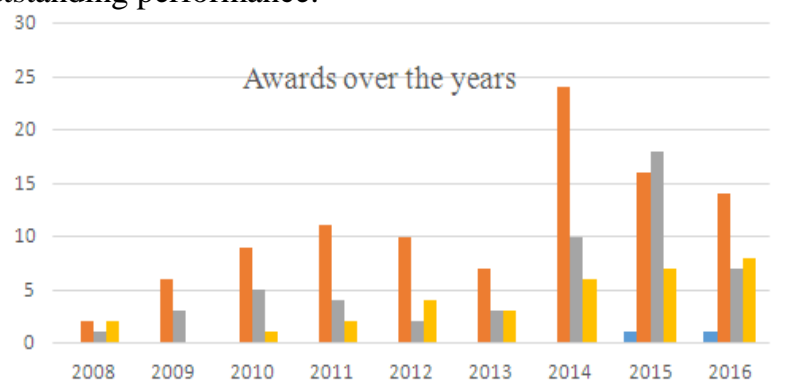

Fig. 2 Awards over the years

In the past 10 years since its establishment, the Ministry of Education, Shanxi Provincial Party Committee and Provincial Government, Education Department, League Committee, Science and Technology Department, Taiyuan University of Science and Technology, and other relevant leaders have visited the team many times to encourage, support and guide the team. The central, Shanxi, Taiyuan television, newspapers, network and other media have reported the team for hundreds of times, the popularity of the team has been greatly expanded, these reports also play an important role in attracting excellent talents for the team and financing. And teachers and the backbone students have been trained for brother colleges in Shanxi Province, the establishment of a robot innovation team plays a good role in radiation.

\section{CONCLUSION}

(1) In order to realize the training goal, the teaching scheme of cultivating strong ability must be cultivated so that students can be trained into high0class scientific and technological innovation talents during the completion of the scientific and technological innovation activities such as the research and development of intelligent control robot.

(2) Strict selection procedures to ensure that outstanding students can enter the scientific and technological innovation team; Make full research in the whole school to ensure that excellent teachers can join the scientific and technological innovation team; Careful selection of science and technology projects to ensure that high-class scientific research projects can be used in scientific and technological innovation team.

(3) Take the sense of achievement as the goal, pay attention to the joint improvement in many aspects, adopt the mode of co-construction and win-win, mobilize the enthusiasm of the team, and realize the healthy, prosperous and sustainable development of the scientific and technological innovation team.

\section{ACKNOWLEDGMENT}

The authors would like to acknowledge the Teaching Reform and Innovation Project of Shanxi Higher Education (No. J2017026) and the Educational Science Research Project of Engineering and Training Instruction Committee of Higher Education Institutions of the Ministry of Education (No. JJ-GX-JY201729) for funding support.

\section{REFERENCES}

[1] Liu X. The Cultivation Approach for the University Students Creative Spirit and Creative Ability[J]. Educational Research, 2008,pp.103-105.

[2] Zhang H, Sun X, Ji C, et al. Opening laboratory to promote spirit of innovation and practice ability of undergraduate students[J]. Experimental Technology \& Management, 2011, pp.16-19.

[3] Yang G L, Zeng D M. Constructing Innovative Education System to Improve the Students' Innovative Spirit and Practical Ability[J]. Research \& Exploration in Laboratory, 2008,pp.4-6.

[4] ZHANG Y,YANG S Y, CHEN H Z. On cultivation means of college students' enterepreneur ship and entrepreneurial ability in new situations [J]. Journal of Hebei University of Engineering (Social Science Edition),2017.pp.4-7.

[5] JIANG Y R,FANG C,XIA J H. Exploration on Cultivating Innovative Ability of Undergraduate According to the Idea of Interdisciplinary [J]. Higher Education Forum,2015.pp.45-48.

[6] Chandler G N, Hanks S H. Measuring the performance of emerging businesses: A validation study [J]. Journal of Business Venturing, 1993,pp.36-42.

[7] ZHAO J,YU P. Promoting Multidisciplinary Innovative Talents Cultivation by Undergraduate Innovative Experiment Program[J]. The Guide of Science \& Education,2017.pp.49-51.

[8] Tan J K, ReyhangulKadir. On the Legal Teaching Reformation Taking the Multidisciplinary Cultivation as the Orientation [J] Journal of Fujian Police College, 2014,pp.99-104.

[9] Lan F S. Gain: to enhance the ideological and political theory class four dimensions of importance [J]. Journal of Jiamusi Vocational Institute,2016,pp.100.

[10] GUO C,WANG X S. Ideological and Political Education in College Should Enable College Students to have a Sense of Achievement[J]. Journal of North China Electric Power University,2017,pp.122-126. 